\title{
Microwave-assisted extraction of essential oil from ginger (Zingiber officinale Rosc.)
}

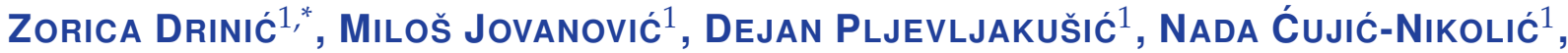 \\ DUBRAVKa BIGOVIĆ ${ }^{1}$, AND KATARINA ŠAVIKIN ${ }^{1}$ \\ ${ }^{1}$ Institute for Medicinal Plants Research "Dr. Josif Pančić", Tadeuša Košćuška 1, 11000 Belgrade, Serbia \\ *Corresponding author: zdrinic@mocbilja.rs
}

Published: December 25, 2021

Received: September 4, 2021

Accepted: October 19, 2021

Published on-line: October 25, 2021

\begin{abstract}
Comparison between conventional and microwave-assisted hydrodistillation at different power levels has been applied for the extraction of essential oil from Zingiber officinale Rosc. rhizome. In addition to the collected essential oils, as the main products, hydrolats were also collected, as valuable by-products from both extraction techniques. A comparison of two applied techniques was done in terms of extraction time, extraction yield, the chemical composition of essential oils and hydrolats, and environmental impact. Microwave-assisted hydrodistillation achieved a higher extraction yield (1.70, 1.70 , and $1.85 \%$ for power levels of 180,360 , and $600 \mathrm{~W}$, respectively) compared to hydrodistillation $(1.50 \%)$. Furthermore, distillation time related to the energy consumption has been reduced from 144 min and $1.44 \mathrm{kWh}$ for conventional hydrodistillation to $37,32,27 \mathrm{~min}$ and $0.11,0.19,0.27 \mathrm{kWh}$ for power levels of 180,360, and $600 \mathrm{~W}$, respectively. Content of $\alpha$-zingiberene in essential oil and hydrolat obtained by hydrodistillation was 29.89 and $6.87 \%$, while content of $\alpha$-zingiberene in essential oils and hydrolats obtained by microwave-assisted hydrodistillation was higher yielding the amounts of $34.12,34.43$, and $42.00 \%$ and $18.70,22.60$, and $32.92 \%$ for power levels of 180,360 , and $600 \mathrm{~W}$, respectively. Microwave-assisted hydrodistillation has proven to be promising technique for the isolation of ginger's essential oil regarding improved yield, reduced time and energy requirements, as well $\mathrm{CO}_{2}$ emissions while maintains oil quality.
\end{abstract}

Key words: hydrosol, essential oil, volatile compounds, ginger, HD, MAHD

http://dx.doi.org/10.5937/leksir2141022D

\section{INTRODUCTION}

Ginger (Zingiber officinale Rosc., Zingiberaceae) is a perennial plant species whose tuberous rhizome is widely used as a very popular spice, for food and beverages flavoring and as a medicinal raw material. The plant is native to Southeast Asia and India, but nowadays it is extensively cultivated due to its commercial importance (Kamaliroosta et al., 2013). Whole or cut, dried ginger rhizomes (Zingiberis rhizoma) with a minimum essential oil content of $1.5 \%(\mathrm{v} / \mathrm{w})$ are official herbal drug according to the European Pharmacopoeia 10.0 (Ph.Eur. 10.0., 2019). Ginger-contained medicines are traditionally used in various gastrointestinal disorders such as loss of appetite, dyspeptic ailments, stomach ache and diarrhea. In rational phytotherapy, as a confirmed safe antiemetic, it is primarily used in the prevention and treatment of postoperative nausea and vomiting, as well as kinetosis (Kamaliroosta et al., 2013; Tóth et al., 2018).

Chemically, about 400 identified ginger ingredients are generally divided into a group of pungent constituents and a group of aromatic constituents. Non-volatile oily compounds (gingerols, shogaols, zingerons, ginger) that contribute to the sweet-spicy taste of ginger are pungent constituents (Kamaliroosta et al., 2013; Talebi et al., 2021). The unique fragrance of ginger comes from essential oil. Its yield and composition depend on the origin of plant, plant genotype, maturity, harvest time, drying and extraction techniques (Ravi Kiran et al., 2013). The main ingredients of the essential oil are sesquiterpene hydrocarbons $\alpha$-zingiberene, $\beta$-sesquiphellandrene, $\beta$ bisabolene, $\alpha$-farnesene, ar-curcumene, and lower content of the monoterpene hydrocarbons and oxygenated monoterpenes (camphene, geraniol, citral, cineol, $\beta$-phellandrene) (Kamaliroosta et al., 2013; Talebi et al., 2021). Conventional hydrodistillation (HD) and steam distillation are still the most commonly used technique for essential oil isolation at both laboratory and industrial levels (Drinić et al., 2020). The main limitations of these traditional distillation techniques are the thermal and/or hydrolytic degradation of esters and polyunsaturated ingredients during prolonged exposure to elevated 
Table 1. Chemical constituents in the Z. officinale rhizome essential oil obtained with hydrodistillation (HD) and microwaveassisted hydrodistillation (MAHD) at different power levels

\begin{tabular}{|c|c|c|c|c|c|c|}
\hline \multirow[b]{2}{*}{$\#$} & \multirow[b]{2}{*}{ Compound } & \multirow[b]{2}{*}{$\mathrm{RI}^{\mathrm{a}}$} & \multirow[b]{2}{*}{$\mathrm{HD}$} & \multicolumn{3}{|c|}{ MAHD } \\
\hline & & & & $180 \mathrm{~W}$ & $360 \mathrm{~W}$ & $600 \mathrm{~W}$ \\
\hline 1 & 2-heptanol & 899.1 & - & 0.04 & 0.08 & - \\
\hline 2 & tricyclene & 927.9 & - & 0.04 & 0.08 & - \\
\hline 3 & $\alpha$-pinene & 938.7 & 2.14 & 1.78 & 1.39 & 0.62 \\
\hline 4 & camphene & 955.5 & 8.61 & 7.13 & 5.93 & 3.02 \\
\hline 5 & sabinene & 978.5 & - & 0.03 & 0.06 & 0.12 \\
\hline 6 & $\beta$-pinene & 982.8 & 0.27 & 0.21 & 0.22 & - \\
\hline 7 & 6-methyl-5-hepten-2-one & 985.7 & 0.76 & 0.35 & 0.27 & 0.08 \\
\hline 8 & myrcene & 991.9 & 1.00 & 0.91 & 0.83 & 0.50 \\
\hline 9 & $\alpha$-phellandrene & 1009.0 & 0.25 & 0.24 & 0.24 & 0.16 \\
\hline 10 & $\beta$-phellandrene & 1036.3 & 6.85 & 6.15 & 5.95 & 5.85 \\
\hline 11 & 1,8-cineole & 1037.8 & 3.52 & 3.14 & 3.80 & 1.15 \\
\hline 12 & terpinolene & 1093.4 & 0.20 & 0.17 & 0.21 & 0.16 \\
\hline 13 & 6-camphenone & 1098.7 & - & - & 0.07 & - \\
\hline 14 & linalool & 1101.2 & 0.37 & 0.40 & 0.46 & 0.40 \\
\hline 15 & citronellal & 1154.7 & 0.19 & 0.20 & 0.22 & 0.19 \\
\hline 16 & camphene hydrate & 1160.5 & - & - & 0.07 & - \\
\hline 17 & iso-chrysanthenol & 1168.0 & - & 0.15 & 0.11 & 0.08 \\
\hline 18 & borneol & 1176.4 & 1.22 & 1.39 & 1.61 & 1.53 \\
\hline 19 & trans-isocitral & 1184.7 & - & 0.07 & 0.11 & - \\
\hline 20 & terpinen-4-ol & 1187.6 & - & 0.11 & 0.13 & 0.12 \\
\hline 21 & $\alpha$-terpineol & 1198.5 & 0.59 & 0.67 & 0.77 & 0.73 \\
\hline 22 & myrtenol & 1207.1 & - & 0.08 & 0.14 & 0.13 \\
\hline 23 & citronellol & 1230.1 & 0.18 & 0.23 & 0.25 & 0.24 \\
\hline 24 & neral & 1246.5 & 3.17 & 3.06 & 3.00 & 2.68 \\
\hline 25 & geraniol & 1256.8 & 0.27 & 0.23 & 0.21 & 0.17 \\
\hline 26 & iso-chrysanthenyl acetate & 1264.8 & - & 0.12 & 0.12 & 0.12 \\
\hline 27 & geranial & 1275.3 & 4.12 & 4.13 & 4.15 & 4.16 \\
\hline 28 & bornyl acetate & 1294.7 & 0.25 & 0.30 & 0.34 & 0.29 \\
\hline 29 & $\delta$-elemene & 1351.3 & - & 0.10 & 0.10 & 0.10 \\
\hline 30 & citronellyl acetate & 1354.4 & - & 0.08 & 0.09 & 0.08 \\
\hline 31 & neryl acetate & 1383.3 & 0.39 & 0.37 & 0.43 & 0.23 \\
\hline 32 & geranyl acetate & 1385.8 & 0.16 & 0.18 & 0.16 & 0.29 \\
\hline 33 & $\beta$-cubebene & 1392.3 & 0.30 & 0.31 & 0.32 & 0.33 \\
\hline 34 & cis-caryophyllene & 1405.9 & 0.51 & 0.55 & 0.61 & 0.62 \\
\hline 35 & $\alpha$-cis-bergamotene & 1413.9 & 0.14 & 0.15 & 0.19 & 0.18 \\
\hline 36 & $\alpha$-himachalene & 1449.5 & 0.21 & 0.23 & 0.24 & 0.29 \\
\hline 37 & sesquisabinene & 1461.3 & 0.32 & 0.32 & 0.28 & 0.24 \\
\hline 38 & trans-9-epi-caryophyllene & 1467.1 & 0.27 & 0.33 & 0.38 & 0.53 \\
\hline 39 & $\gamma$-himachalene & 1483.5 & 0.18 & 0.20 & 0.20 & 0.21 \\
\hline 40 & ar-curcumene & 1494.7 & 4.44 & 3.10 & 2.87 & 2.41 \\
\hline 41 & germacrene D & 1503.0 & 1.38 & 1.97 & 2.69 & 1.89 \\
\hline 42 & $\alpha$-zingiberene & 1510.6 & 29.89 & 34.12 & 34.43 & 42.00 \\
\hline 43 & $\beta$-bisabolene & 1515.2 & 3.90 & 5.15 & 6.92 & 7.38 \\
\hline 44 & $\gamma$-cadinene & 1518.7 & 0.95 & 1.12 & 1.41 & 0.45 \\
\hline 45 & 7-epi- $\alpha$-selinene & 1522.7 & 6.71 & 2.23 & - & - \\
\hline 46 & $\beta$-sesquiphellandrene & 1540.3 & 11.16 & 11.67 & 11.48 & 12.89 \\
\hline 47 & trans- $\gamma$-bisabolene & 1546.0 & 0.32 & 0.40 & 0.47 & 0.58 \\
\hline 48 & longipinanol & 1567.4 & 0.78 & 0.98 & 0.06 & 1.46 \\
\hline 49 & trans-nerolidol & 1570.9 & 0.39 & 0.77 & 1.31 & - \\
\hline 50 & germacrene D-4-ol & 1604.1 & - & - & - & 0.09 \\
\hline 51 & trans-sesquisabinene & 1604.6 & 0.61 & 0.63 & 0.63 & 0.71 \\
\hline 52 & viridiflorol & 1628.6 & 0.78 & 0.80 & 0.89 & 0.98 \\
\hline 53 & 1-epi-cubenol & 1645.5 & 0.55 & 0.57 & 0.60 & 0.70 \\
\hline 54 & allo-aromadendrene epoxide & 1656.4 & 0.36 & 0.37 & 0.39 & 0.47 \\
\hline 55 & $\beta$-eudesmol & 1679.1 & 0.44 & 0.52 & 0.62 & 0.74 \\
\hline 56 & epi- $\alpha$-bisabolol & 1703.1 & 0.90 & 0.97 & 0.93 & - \\
\hline 57 & 2-trans-6-cis-farnesal & 1716.2 & - & 0.12 & 0.24 & 1.12 \\
\hline 58 & 2-cis-6-trans-farnesol & 1727.9 & - & 0.15 & 0.06 & 0.29 \\
\hline 59 & cis-nuciferol & 1748.9 & - & 0.10 & 0.09 & 0.11 \\
\hline \multirow[t]{6}{*}{60} & 2-trans-6-trans-farnesal & 1754.1 & - & 0.11 & 0.11 & 0.14 \\
\hline & Non-oxygenated monoterpenes & & 19.33 & 16.62 & 14.84 & 10.43 \\
\hline & Oxygenated monoterpenes & & 14.43 & 14.91 & 16.22 & 12.59 \\
\hline & Non-oxygenated sesquiterpenes & & 60.68 & 61.95 & 62.58 & 70.10 \\
\hline & Oxygenated sesquiterpenes & & 4.80 & 6.09 & 5.93 & 6.80 \\
\hline & Other & & 0.76 & 0.43 & 0.43 & 0.08 \\
\hline
\end{tabular}

${ }^{a}$ RI, retention indices as determined on HP-5 column using homologous series of $C_{8}-C_{30}$ alkanes. 
temperature in an aqueous medium. Loss of volatile compounds may also contribute to reduced extraction efficiency of the essential oil. Furthermore, traditional techniques as time and energy demanding are unfavorable for modern industry that aspires to establish economically and ecologically friendly extractions techniques (Ferhat et al., 2007). Considering these facts, the development of innovative green extraction techniques to overcome the drawbacks of traditional techniques is necessary.

In the last decade, microwave-assisted hydrodistillation (MAHD) has been affirmed as an effective, energy- and timesaving extraction technique for essential oils isolation (Drinić et al., 2020; Golmakani and Rezaei, 2008). Significant acceleration of the extraction process was achieved via rapid microwave heating and energy transfer generated by the electromagnetic field. Actually, traditional heating arises by thermal energy transferring from the heating surface, across extraction medium, along the temperature gradient. In a contrast of microwave heating, where the energy transmission via electromagnetic radiation is contactless and instantaneous. The electromagnetic radiation induces reorientation of dipole molecules (dipole rotation) and electrophoretic ion movement (ionic conduction). This generates friction between the molecules, creates kinetic energy and consequently induces a rapid increase in temperature. The MAHD technique is applicable in the laboratory and on an industrial scale (Radivojac et al., 2020; Vinatoru et al., 2017).

The main objective of this research was to compare the qualitative and quantitative composition of Zingiberis rhizoma essential oils and hydrolats obtained using traditional HD and novel MAHD methods. Essential oils and hydrolats were analyzed by gas chromatography-mass spectrometry (GC-MS). Additional objectives of the research were to compare time and energy consumption, as well as the impact of applied methods on the environment.

\section{MATERIALS AND METHODS}

\subsection{Standards and reagents}

Ethanol, distilled water, and $n$-hexane were purchased from Zorka Pharma, Šabac (Serbia). Sodium sulfate anhydrous $\left(\mathrm{Na}_{2} \mathrm{SO}_{4}\right)$ was purchased from Sigma Chemicals Co. (USA).

\subsection{Plant material}

Zingiber officinale Rosc. rhizome was obtained by local market. Fresh plant material was cut and air dried at ambient temperature to residual humidity lower than $5 \%$. Before extraction process, plant material was ground in a domestic blender (CISA Cedacería Industrial, Barcelona, Spain).

\subsection{Essential oils, hydrolats}

Conventional HD and MAHD techniques were applied for the isolation of essential oils and hydrolats. HD was performed using a Clevenger type apparatus according to the procedure I of the Yugoslavian Pharmacopoeia IV (Ph.Jug.IV, 1951). MAHD was performed using the specially created system, consisting of the microwave oven (HMT 72M450, Bosch, Gerlingen, Germany) connected to the Clevenger type apparatus. The water/plant ratio was the same for HD and MAHD, 10:1 (w/w). MAHD was performed on three different power levels (180, 360 , and $600 \mathrm{~W}$ ) until no more essential oil was obtained (20 $\mathrm{min})$. The time required to reach the final amount of essential oil, i.e., time required for starting the extraction and time for essential oil isolation, present a total extraction time. The essential oils were collected, and dried over anhydrous sodium sulphate. The essential oil yield, expressed as a percentage, was calculated on a moisture-free basis. Oil samples $(20 \mu \mathrm{L})$ were dissolved in $96 \%$ ethanol $(2 \mathrm{~mL})$ and stored at $4{ }^{\circ} \mathrm{C}$ until further analysis.

Hydrolats were collected from the burette after HD and MAHD, extracted with $\mathrm{n}$-hexane $(5 \mathrm{~mL}$ of hydrolats with 3 $\times 1 \mathrm{~mL} n$-hexane), hexane fractions were collected, combined and stored in the freezer until further analysis.

\subsection{Chemical analysis of essential oil and hydrolats}

The chemical composition of the essential oils and hydrolats was analyzed using GC/MS technique. GC/MS analyses were performed on a Shimadzu GCMS-QP2010 ultra mass spectrometer fitted with a flame ionic detector and coupled with a GC2010 gas chromatograph. The InertCap5 capillary column $(60.0 \mathrm{~m} \times 0.25 \mathrm{~mm} \times 0.25 \mu \mathrm{m})$ was used for separation. Helium (He), at a split ratio of 1:5 and a linear velocity of 35.2 $\mathrm{cm} / \mathrm{s}$ was used as carrier gas. Initially, the oven temperature was $60{ }^{\circ} \mathrm{C}$, which was held for $4 \mathrm{~min}$, then increased to $280^{\circ} \mathrm{C}$ at a rate of $4{ }^{\circ} \mathrm{C} / \mathrm{min}$, and held for $10 \mathrm{~min}$. The injector and detector temperatures were $250{ }^{\circ} \mathrm{C}$ and $300{ }^{\circ} \mathrm{C}$, respectively. The ion source temperature was $200^{\circ} \mathrm{C}$. The identification of the constituents was performed by comparing their mass spectra and retention indices (RIs) with those obtained from authentic samples and/or listed in the NIST/Wiley mass-spectra libraries, using different types of searches (PBM/NIST / AMDIS) and available literature data (Adams, 2007; Hochmuth, 2006).

\subsection{Environmental impact of applied techniques}

Regarding environmental impact, electrical consumption and $\mathrm{CO}_{2}$ emission were calculated. The electrical consumption (A) for HD and MAHD was calculated as the electrical power for a time, using the following equation:

$$
A=P \times t,
$$

where $\mathrm{A}$ is electrical consumption ( $\mathrm{kWh}$ ), $\mathrm{P}$ is electrical power $(\mathrm{kW})$ and $\mathrm{t}$ is time (h). According to Ferhat et al. (2006) to obtain $1 \mathrm{kWh}$ from coal or fuel, $800 \mathrm{~g}$ of $\mathrm{CO}_{2}$ will be emitted in the atmosphere during the combustion of fossil fuel. $\mathrm{CO}_{2}$ emission can be described by the equation:

$$
E_{\mathrm{CO}_{2}}=\frac{A \times 800}{1000}
$$

where $\mathrm{E}_{\mathrm{CO}_{2}}$ is $\mathrm{CO}_{2}$ emission $(\mathrm{kg})$ and $\mathrm{A}$ is electric consumption (kWh).

\section{RESULTS AND DISCUSSION}

\subsection{Essential oil yield}

The essential oil for MAHD at power level 180 and $360 \mathrm{~W}$ was same and yielded $1.70 \%$, while at power level $600 \mathrm{~W}$ it was slightly higher and yielded $1.85 \%$. The yield of essential oil of the HD method was $1.5 \%$, and lower compared to the method of MAHD extraction. Similar to our results, (Govindarajan and Connell, 1983) reported that yield of ginger essential oil ranged from 1.0 to $3.0 \%$. Total extraction time was 37, 32, and $27 \mathrm{~min}$ for MAHD at 180, 360, and $600 \mathrm{~W}$, respectively, while for HD it was $144 \mathrm{~min}$. Time required to start the extraction was 17, 12, 7, and $24 \mathrm{~min}$ for MAHD at 180, 360, and 600 $\mathrm{W}$, and HD, respectively. The extraction time was reduced by about $70-80 \%$ using microwaves. High reduction in the processing time is probably due to different mechanism of heating in MAHD and HD. Namely, the heating process in HD is conditioned by the transfer of heat from the heating medium to the interior of the samples, while the microwave heating is volumetrically dispersing within the sample and is based on ionic conduction and dipole rotation (Veggi et al., 2012). As microwaves interact with the free water molecules present in the gland and vascular systems, local heating occurs 
Table 2. Chemical constituents in the Z. officinale rhizome hydrolat obtained by hydro-distillation (HD) and microwave-assisted hydro-distillation (MAHD) at different power levels

\begin{tabular}{|c|c|c|c|c|c|c|}
\hline \multirow[b]{2}{*}{$\#$} & \multirow[b]{2}{*}{ Compound } & \multirow[b]{2}{*}{$\mathrm{RI}^{\mathrm{a}}$} & \multirow[b]{2}{*}{ HD } & \multicolumn{3}{|c|}{ MAHD } \\
\hline & & & & $180 \mathrm{~W}$ & $360 \mathrm{~W}$ & $600 \mathrm{~W}$ \\
\hline 1 & hexanal & 799.4 & 2.05 & - & - & - \\
\hline 2 & 2-heptanol & 898.9 & 3.19 & 2.89 & 1.21 & - \\
\hline 3 & $\alpha$-pinene & 938.9 & - & - & 0.71 & 0.50 \\
\hline 4 & camphene & 954.8 & 1.69 & 2.75 & 3.30 & 2.52 \\
\hline 5 & 6-methyl-5-hepten-2-one & 986.1 & 12.26 & 5.70 & 2.10 & - \\
\hline 6 & $\alpha$-phellandrene & 1035.5 & - & 0.37 & 3.24 & 3.14 \\
\hline 7 & 1,8-cineole & 1037.4 & 27.62 & 21.21 & 16.41 & 8.57 \\
\hline 8 & linalool & 1101.6 & 4.68 & 3.12 & 2.50 & 1.45 \\
\hline 9 & camphor & 1154.6 & - & - & 0.69 & - \\
\hline 10 & borneol & 1176.5 & 17.30 & 15.20 & 10.00 & 6.35 \\
\hline 11 & terpinen-4-ol & 1186.2 & - & - & 0.72 & - \\
\hline 12 & $\alpha$-terpineol & 1198.7 & 11.76 & 9.15 & 6.14 & 3.58 \\
\hline 13 & neral & 1245.6 & 1.46 & 3.45 & 3.81 & 3.67 \\
\hline 14 & geraniol & 1256.7 & 2.50 & 1.05 & 0.89 & 0.54 \\
\hline 15 & cis-chrysanthenyl acetate & 1262.4 & 2.15 & 1.82 & 1.01 & 0.58 \\
\hline 16 & geranial & 1274.1 & 1.67 & 3.46 & 4.63 & 5.06 \\
\hline 17 & ar-curcumene & 1493.6 & - & 2.56 & 3.04 & 4.32 \\
\hline 18 & germacrene D & 1502.7 & - & 0.85 & 0.99 & 1.37 \\
\hline 19 & $\alpha$-zingiberene & 1505.9 & 6.87 & 18.70 & 22.60 & 32.92 \\
\hline 20 & trans, trans- $\alpha$-farnesene & 1513.0 & - & - & 2.52 & 3.49 \\
\hline 21 & 7-epi- $\alpha$-selinene & 1518.2 & - & - & - & 1.00 \\
\hline 22 & $\alpha$-bisabolene & 1520.2 & 1.74 & 3.14 & 5.53 & 6.73 \\
\hline 23 & $\beta$-sesquiphellandrene & 1537.3 & 3.05 & 4.58 & 7.96 & 11.42 \\
\hline 24 & longipinanol & 1567.3 & - & - & - & 0.96 \\
\hline 25 & trans-sesquisabinene hydrate & 1604.6 & - & - & - & 0.84 \\
\hline 26 & $\alpha$-bisabolol & 1628.5 & - & - & - & 0.97 \\
\hline
\end{tabular}

${ }^{a}$ RI, retention indices as determined on HP-5 column using homologous series of $C_{8}-C_{30}$ alkanes.

resulting in cell expansion and rupture allowing the easier isolation of the essential oil.

The difference in time required to start the extraction time at different power levels are correlated to the different density of the waves. The lowest used microwave power has the lowest density waves and therefore it has the longest time required to start extraction. Total extraction time was much lower in MAHD than HD even at the lowest microwave power (180 W). Reduction in the extraction time of MAHD compared to HD was previously reported (Ferhat et al., 2007; Golmakani and Rezaei, 2008; Rezvanpanah et al., 2008).

\subsection{Composition of essential oils and hydrolats}

The composition of the essential oil of ginger rhizome obtained by MAHD and conventional HD method is given in Table 1. The chemical composition of the essential oils obtained by both applied methods were found to be almost the same qualitatively, whereas some quantitative differences were observed. In the HD-obtained essential oil 43 compounds were found, while the MAHD-obtained essential oils contained 57, 58 , and 51 compounds for power level 180, 360, and $600 \mathrm{~W}$, respectively. The dominant compound in all samples was $\alpha$ zingiberene (29.9-42.0\%) followed by camphene (3.0-8.6 \%), $\beta$-phellandrene (5.8-6.8\%), and 1,8-cineole (1.1-3.5\%). Our findings are in accordance with previously reported data (Kamaliroosta et al., 2013; Ravi Kiran et al., 2013; Stoyanova et al., 2006). Content of $\alpha$-zingiberene was higher in essential oils obtained by MAHD $(34.12,34.43$, and $42 \%$ for MAHD at 180 , 360 , and $600 \mathrm{~W}$, respectively compared to $29.89 \%$ for HD). The content of other major compounds was approximately the same for HD and MAHD, except for camphene, 1,8-cineole and ar-curcumene for HD and MAHD at $600 \mathrm{~W}$, where the content of these compounds was about two-fold higher in $\mathrm{HD}$, as well as for $\beta$-bisabolene whose content was about twofold higher in the MAHD. About $80 \%$ of the identified com- pounds belong to the group of non-oxygenated terpenes, most of which (60-70\% of total oil) belong to sesquiterepenes, while a smaller part (10-19\% of total oil) belongs to monoterpene hydrocarbons. The amount of non-oxygenated compounds in essential oil obtained by HD and MAHD at 180, 360, and 600 W was $80.01,78.57,77.42$, and $80.53 \%$, respectively, of which the sesquiterpenes take share $60.68,61.59,62.58$ and $70.10 \%$. The content of oxygenated components was about $20 \%$ in all analyzed samples, where the portion of monoterpene fraction was two to three times higher than the portion of sesquiterpene fraction. Although, many authors reported that essential oil obtained by MAHD contains higher amount of oxygenate compounds comparing to the HD (Drinić et al., 2020; Ferhat et al., 2006; Filly et al., 2014), we cannot confirm that pattern based on our results. Similar to our results, Karakaya et al. (2014) reported that the concentration of oxygenated and nonoxygenated compounds was almost the same in both methods, MAHD and HD.

The major components in essential oils were also the major components in hydrolats with different percent in different hydrolats samples (Table 2). The hydrolats obtained by HD and MAHD at $360 \mathrm{~W}$ had 1,8-cineole as dominant compound with relative percentage of 27.62 and 21.21, respectively, followed by borneol (17.30 and $15.20 \%), \alpha$-zingiberene (6.87 and 18.70 $\%), \alpha$-terpineol (11.76 and 9.15\%), linalool (4.68 and $3.12 \%)$, $\beta$-sesquiphellandrene (3.05 and $4.58 \%$ ), geranial (1.67 and 3.46 $\%)$, and $\beta$-bisabolene (1.74 and $3.14 \%$ ). The most abundant compound in hydrolats obtained by MAHD at 360 and $600 \mathrm{~W}$ was $\alpha$-zingiberene with relative percentage of 22.60 and 32.92, respectively, followed by 1,8-cineole (16.41 and $8.57 \%$ ), borneol (10.00 and $6.35 \%), \beta$-sesquiphellandrene (7.96 and 11.42 $\%), \beta$-bisabolene (5.53 and $6.73 \%$ ), $\alpha$-terpineol (6.14 and 3.58 $\%)$, geranial (4.63 and $5.06 \%$ ), and linalool (2.50 and $1.45 \%$ ). Same trend, that the major compounds in essential oil were also major compounds in hydrolats, was reported previously 
Table 3. Process parameters of microwave-assisted hydrodistillation (MAHD) compared with standard hydrodistillation (HD)

\begin{tabular}{|c|c|c|c|c|c|c|}
\hline $\begin{array}{l}\text { Distillation } \\
\text { method }\end{array}$ & $\begin{array}{r}\text { Process } \\
\text { time }\end{array}$ & $\begin{array}{r}\text { Time } \\
\text { saving }\end{array}$ & $\begin{array}{r}\text { Energy } \\
\text { consumption }\end{array}$ & $\begin{array}{l}\text { Energy } \\
\text { saving }\end{array}$ & $\begin{array}{r}\mathrm{CO} 2 \\
\text { emission }\end{array}$ & $\begin{array}{r}\mathrm{CO} 2 \\
\text { emission } \\
\text { reduction }\end{array}$ \\
\hline & {$[\mathrm{min}]$} & {$[\%]^{\mathrm{a}}$} & {$[\mathrm{kWh}]$} & {$[\%]$} & {$[\mathrm{kg}]$} & {$[\%]$} \\
\hline HD (600W) & 144 & $\mathrm{n} / \mathrm{a}$ & 1.44 & $\mathrm{n} / \mathrm{a}$ & 1.15 & $\mathrm{n} / \mathrm{a}$ \\
\hline MAHD $180 \mathrm{~W}$ & 37 & 74.3 & 0.11 & 93.19 & 0.09 & 92.28 \\
\hline MAHD $360 \mathrm{~W}$ & 32 & 77.7 & 0.19 & 88.22 & 0.15 & 86.65 \\
\hline MAHD $600 \mathrm{~W}$ & 27 & 81.2 & 0.27 & 84.75 & 0.22 & 81.19 \\
\hline
\end{tabular}

(Paolini et al., 2008; Shahani et al., 2011). Obtained hydrolats can be considered for use in cosmetic and pharmaceutical industries due to valuable chemical constituents.

\subsection{Environmental impact}

Concerning environmental impact, the advantages of obtained essential oil from Z. officinale rhizome using MAHD method have been presented in Table 3. MAHD had smaller electrical consumption $(0.11,0.19$, and $0.27 \mathrm{kWh}$ for power level 180,360 , and $600 \mathrm{~W})$ compared to HD (1.44 kWh), as well as, smaller $\mathrm{CO}_{2}$ emission $(0.09,0.15$, and $0.22 \mathrm{~kg}$ for MAHD at 180,360 , and $600 \mathrm{~W}$, respectively, and $1.15 \mathrm{~kg}$ for HD). Using the MAHD method energy saving was from 84.75 to $91.15 \%$ compared to the $\mathrm{HD}$, while $\mathrm{CO}_{2}$ emission was reduced for 81.19 to 92.28 $\%$. Electrical consumption and $\mathrm{CO}_{2}$ emission are related to the extraction time. Since the extraction time, the required energy, and $\mathrm{CO}_{2}$ emission for MAHD are significantly reduced compared to HD, it is affirmed as a more environmentally friendly approach.

\section{CONCLUSION}

Yield of ginger rhizome essential oil improvement was achieved using MAHD extraction method, with no significant differences in the chemical composition comparing with conventional HD. About $80 \%$ of the identified compounds belong to the group of non-oxygenated terpenes with $\alpha$-zingiberene, camphene, $\beta$-phellandrene and 1,8-cineole as dominant compounds. Extraction time was significantly reduced in the case of MAHD (27-37 min compared to $144 \mathrm{~min}$ ). MAHD has been shown as more environmentally friendly approach with electrical consumption $0.11-0.27 \mathrm{kWh}$ compared to $1.44 \mathrm{kWh}$ and $\mathrm{CO}_{2}$ emission $0.09-0.22 \mathrm{~kg}$ compared to $1.14 \mathrm{~kg}$. As hydrolat represent a by-product of HD process, additional aim of this study was also to investigate the chemical composition of obtained hydrolat so that its use can be indicated for different product of cosmetic and pharmaceutical industries. The dominant compound in hydrolats obtained by HD and MAHD at $180 \mathrm{~W}$ was 1,8-cineol, while in hydrolats obtained by MAHD at 360 and $600 \mathrm{~W}$ was $\alpha$-zingiberene. Considering that the main component of ginger essential oil is $\alpha$-zingiberene, and its content was the highest in essential oil and hydrolat obtained by MAHD at $600 \mathrm{~W}$, it can be marked as the best of tested power level. Therefore, it can be concluded that MAHD is a good alternative for the extraction of essential oil from Z. officinale rhizome since it provides essential oils of similar quality to conventional HD while reducing the time of the process, electrical consumption, $\mathrm{CO}_{2}$ emission, and increase the yields.

\section{ACKNOWLEDGMENTS}

This work was supported by the Ministry of Education, Science and Technological Development of the Republic of Serbia, grant number 451-03-68/2020-14/200003.

\section{REFERENCES}

Adams, R. P. (2007). Identification of Essential Oil Components by Gas Chromatography/mass Spectorscopy, Allured Publishing Corporation. Google-Books-ID: 9ut3PQAACAAJ.

Drinić, Z., Pljevljakušić, D., Živković, J., Bigović, D. and Šavikin, K. (2020) Microwave-assisted extraction of $O$. vulgare L. spp. hirtum essential oil: Comparison with conventional hydro-distillation, Food and Bioproducts Processing 120: 158-165.

Ferhat, M. A., Meklati, B. Y., Smadja, J. and Chemat, F. (2006). An improved microwave Clevenger apparatus for distillation of essential oils from orange peel, Journal of Chromatography A 1112(1-2): 121126.

Ferhat, M. A., Tigrine-Kordjani, N., Chemat, S., Meklati, B. Y. and Chemat, F. (2007). Rapid extraction of volatile compounds using a new simultaneous microwave distillation: Solvent extraction device, Chromatographia 65(3-4): 217-222.

Filly, A., Fernandez, X., Minuti, M., Visinoni, F., Cravotto, G. and Chemat, F. (2014). Solvent-free microwave extraction of essential oil from aromatic herbs: From laboratory to pilot and industrial scale, Food Chemistry 150: 193-198.

Golmakani, M.-T. and Rezaei, K. (2008). Comparison of microwaveassisted hydrodistillation withthe traditional hydrodistillation method in the extraction of essential oils from Thymus vulgaris L., Food Chemistry 109(4): 925-930.

Govindarajan, V. S. and Connell, D. W. (1983). Ginger - chemistry, technology, and quality evaluation: Part 1, Critical Reviews in Food Science and Nutrition 17(1): 1-96.

Hochmuth, D. (2006). Massfinder 3: Software for GC/MS interpretation and presentation, mass spectral library administration. Hamburg, Germany.

Kamaliroosta, Z., Kamaliroosta, L. and Elhamirad, A. H. (2013). Isolation and identification of ginger essential oil, Journal of Food Biosciences and Technology 3: 73-80.

Karakaya, S., El, S. N., Karagozlu, N., Sahin, S., Sumnu, G. and Bayramoglu, B. (2014). Microwave-assisted hydrodistillation of essential oil from rosemary, Journal of Food Science and Technology 51(6): 10561065.

Paolini, J., Leandri, C., Desjobert, J.-M., Barboni, T. and Costa, J. (2008). Comparison of liquid-liquid extraction with headspace methods for the characterization of volatile fractions of commercial hydrolats from typically Mediterranean species, Journal of Chromatography A 1193(1 2): 37-49.

Ph.Eur. 10.0. (2019). European Pharmacopoeia 10.0., Council of Europe, Strasbourg Cedex, France.

Ph.Jug.IV (1951). Pharmacopoea Jugoslavica, Vol. 2, $4^{\text {th }}$ edn, Federal Institute of Public Health, Belgrade, Yugoslavia.

Radivojac, A., Bera, O., Micić, D., Đurović, S., Zeković, Z., Blagojević, 
S. and Pavlić, B. (2020). Conventional versus microwave-assisted hydrodistillation of sage herbal dust: Kinetics modeling and physicochemical properties of essential oil, Food and Bioproducts Processing 123: $90-101$.

Ravi Kiran, C., Chakka, A. K., Padmakumari Amma, K., Nirmala Menon, A., Sree Kumar, M. and Venugopalan, V. (2013). Essential oil composition of fresh ginger cultivars from North-East India, Journal of Essential Oil Research 25(5): 380-387.

Rezvanpanah, S., Rezaei, K., Razavi, S. H. and Moini, S. (2008). Use of microwave-assisted hydrodistillation to extract the essential oils from Satureja hortensis and Satureja montana, Food Science and Technology Research 14(3): 311-314.

Shahani, S., Monsef-Esfahani, H. R., Hajiaghaee, R. and Gohari, A. R. (2011). Chemical composition of essential oil and hydrolat of Geum iranicum Khatamaz, Journal of Essential Oil Research 23(6): 29-33.

Stoyanova, A., Konakchiev, A., Damyanova, S., Stoilova, I. and Suu, P. T. (2006). Composition and antimicrobial activity of ginger essential oil from Vietnam, Journal of Essential Oil Bearing Plants 9(1): 93-98.

Talebi, M., İlgün, S., Ebrahimi, V., Talebi, M., Farkhondeh, T., Ebrahimi, H. and Samarghandian, S. (2021). Zingiber officinale ameliorates Alzheimer's disease and cognitive impairments: Lessons from preclinical studies, Biomedicine \& Pharmacotherapy 133: 111088.

Tóth, B., Lantos, T., Hegyi, P., Viola, R., Vasas, A., Benkő, R., Gyöngyi, Z., Vincze, r., Csécsei, P., Mikó, A., Hegyi, D., Szentesi, A., Matuz, M. and Csupor, D. (2018). Ginger (Zingiber officinale): An alternative for the prevention of postoperative nausea and vomiting. A meta-analysis, Phytomedicine 50: 8-18.

Veggi, P. C., Martinez, J. and Meireles, M. A. A. (2012). Fundamentals of microwave extraction, in F. Chemat and G. Cravotto (eds), Microwaveassisted extraction for bioactive compounds, Springer US, Boston, MA, pp. 15-52. Series Title: Food Engineering Series.

Vinatoru, M., Mason, T. and Calinescu, I. (2017). Ultrasonically assisted extraction (UAE) and microwave assisted extraction (MAE) of functional compounds from plant materials, TrAC Trends in Analytical Chemistry 97: 159-178. 